\title{
The Educational Processes Between Program and Places
}

\author{
ALESSANDRO MASSARENTE \\ Department of Architecture, \\ University of Ferrara
}

KEYWORDS

mutational, recycling, identity,

adaptive design tool, contamination 
It is well known that programs and places are agents of educational process, but the interaction between them is very different during each of the 5 years of an architectural degree course.

Since its launch in 1991, Ferrara school of architecture has experimented a new teaching method in Italy based on interdisciplinary laboratories, inspired to the Bologna Agreement. The themes on which these laboratories were based were mainly referred to project of new settlements.

This interaction through design between disciplines and new settlements was for many years in Italy the leitmotif of teaching methods until the beginning of the new century, when following the building boom it was clear how the speculative bubble would burst out loud, leading to a revision of the global economic system and to the consequent effects on the architectural design role. It was precisely from those years that in Ferrara the introduction of themes related to the recovery of disused or fragile areas was started, with particular attention to the relationship between built landscape, dismissed areas and regeneration processes.

The phenomena linked to the economic crisis, which started with the failure of the global financial model, have produced deep social transformations for significant parts of the population. The planetary dimension of the effects of this crisis are added to the dynamics produced by migratory phenomena and to the consequences of the energy transition, getting their effects particularly in those places where these tensions are most evident.

For several years, in particular in the Architectural Design Laboratories of the 3rd year of the 5 years degree course of Architecture in Ferrara, we have worked with students trying to involve, apart from the aspects of disciplines connected to architectural design, differently conjugated, also those of social, economic and environmental nature.

For example, design exercises have been carried out on some places considered as highly 'mutational': industrial area of the ZIP in Padua (one of the most important north-east development poles planned in the 1950s in the industrial Po valley system and today kept by deep transformations); Macrolotto $\mathrm{O}$ in Prato (historical textile production center in Tuscany where the largest Chinese community in Europe resides); Marshal Tito Barracks in Sarajevo (destined to a new university campus and possible occasion to regenerate a part of the city where the wounds left by the Balkan conflict are still evident).

In Sarajevo, students were asked to explore the project site through 4 progressive exercises: using mapping practices coming from cartographies to read mobility, energetic, natural 
and societal networks in the city; representing some elements (soil, walls, roofs, spaces, environment, routes, visions) to reveal some hidden characters of the urban place; defining spatial concepts through which is possible to compare and intertwine parts of a university campus; developing urban strategies through overlapping of different scenarios coming from an open debate among group of students.

These evocatively significant places played a fundamental role to make students understand the importance and value of operating in problematic urban places through the use of strategies that can be applied within contexts they will face once they graduate.

The goals behind the redefinition of these places were:

- to define the appropriate process through which the program becomes a tool for exploring reality through strategies of knowledge / interpretation / transformation capable of holding together characters and mutations of the place, new needs expressed by people and social networks, in a perspective of sustainable development;

- broaden the concept of recycling, moving it from the traditional one related only to material objects to a concept centered on second life and renew life of both places and communities; - to identify adaptive design tools, through which is possible to define a new alphabet, composed by signs and meanings capable of translating into technical and social interventions the identity values expressed by local communities and changing differences typical of the contemporary world.

The redefinition of these 'mutational' places in the cities takes on the characteristics of a work of contamination between heritage, identity, new modes of use, participation practices of local communities in the dynamics of transformation underway.

Through these educational processes, students and profes$\stackrel{N}{N}$ sors can explore some sensitive points of intensity, strategic areas, places of sharing, occupied spaces, relationships in continuous negotiation: foundation of that genetic heritage that will be able to produce new social forms. We can consider them new opportunities through which architectural design tools could start acting, using involuntary morphologic principles that, if properly addressed, can trigger new mutations within the urbanized territory. 


\section{REFERENCES}

Z. Bauman, In Search of Politics, 1999

J. Rifkin, The Third Industrial Revolution: How Lateral Power is Transforming Energy, the Economy, and the World, 2011 A new way to live Sarajevo. The regeneration of the Marshall Tito Barracks. Exhibition of projects of students of Ferrara Design Labs, DA DANI Arhitecture Days of Architecture, Faculty of Architecture, University of Sarajevo, June 2019

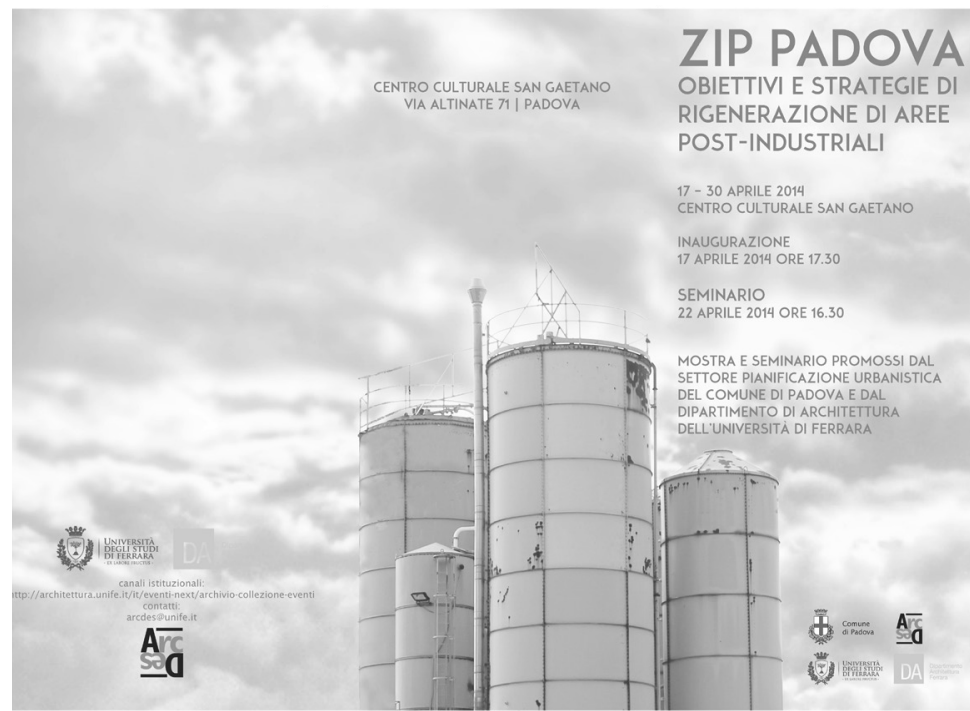

1: ZIP Padova, Exhibition and Conference presentation of Labs projects, Cultural Center San Gaetano, Padova, April 2014 


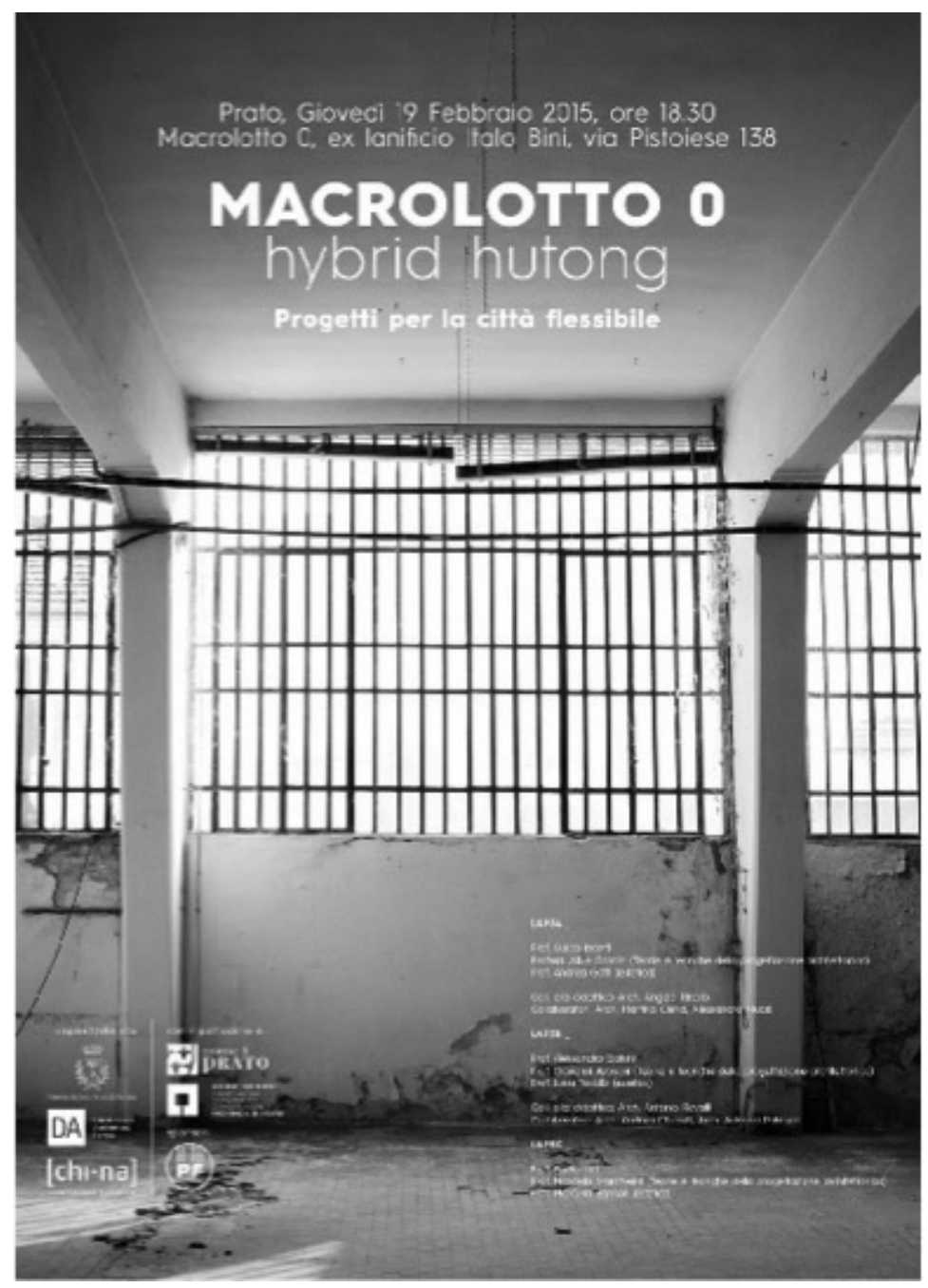

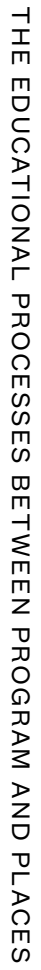

2: Macrolotto 0 Hybrid Hutong, Exhibition of Labs projects, Prato, Febraury 2015 


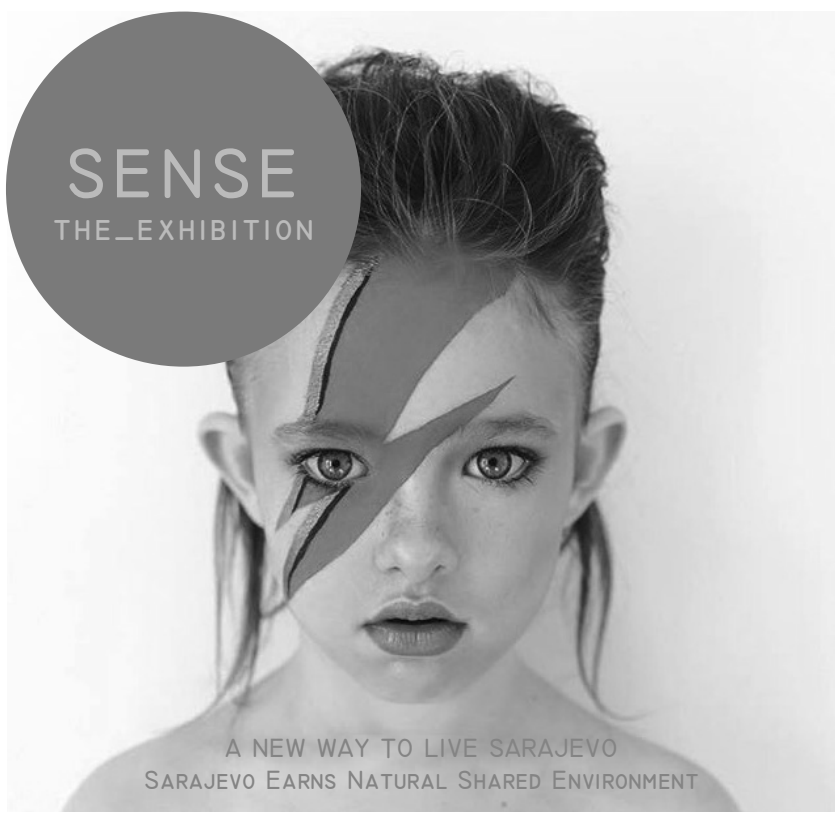

The Regeneration of the Marshall tito BarRacks

EXHIBITON OF THE PROJECTS BY THE STUDENTS OF UNIVERSITY OF FERRARA DESIGN LAB

DAYS OF ARCHITECTURE 2019 | 06.0609 .06 @ SARAJEVO FACULTY OF ARCHITECTURE | UNIVERSITY OF SARAJEVO

University of Ferrara |Department of Architecture

Architecture Master Degree Program | Architectural Design Labs

IIIA Prof. Alessandro Cambi, IIIB Prof. Alessandro Gaiani, IIIC Prof. Alessandro Massarente

Modules Tutors: IIIA Alice Gardini, WIIB Guido Incerti, IIIC Alessandro Tessari Collaboration Assistants: Elena Guideti, Giovanni Bazar

Workshop and Exhibition coordinator: Guido Incerti, Richard Lee Peragine
In collaboration with : DA Dani Arhitecture I Days of Architecure and Faculty of Architecture, University of Sarajevo

Dean. prot. mr. Meviudin Zecevic,
Vice dean for intemational relations prof.dr. Amir Causevic

Prof. dr. Adnan Pasic, Prof. dr Erdin Salihovic, doc.dr. Mladen Burazor

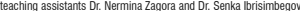
Collaboration assistants: MA Zulejha Zatric, MA Aida Botonjic, MA Emina Alic

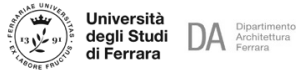

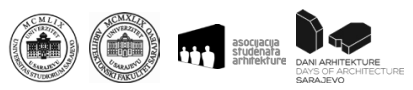

3: Marshall Tito Barracks, DA DANI Arhitecture Days of Architecture, Faculty of Architecture, University of Sarajevo, Sarajevo, June 2019

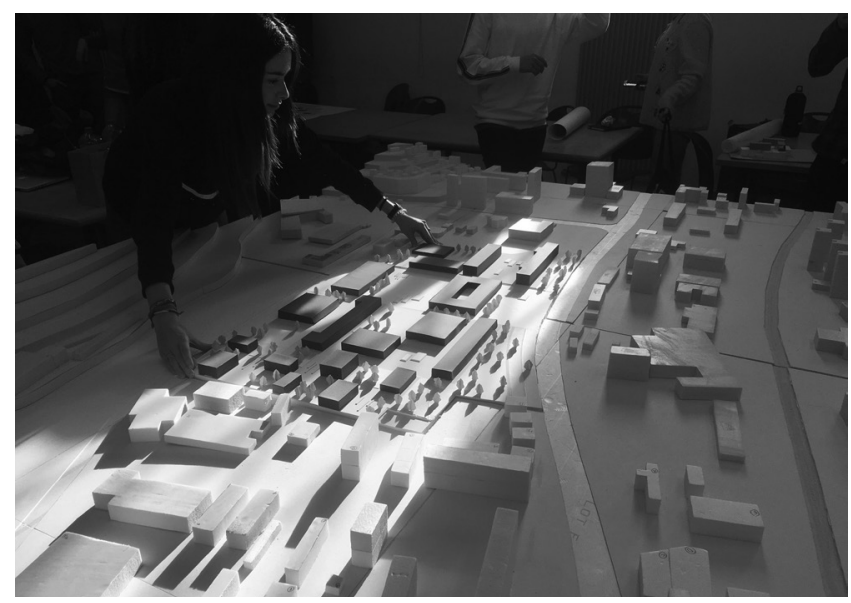

4: One of the site models developed by students 